Brit. J. industr. Med., 1958, 15, 38.

\title{
HEAT STRESS IN NON-FERROUS FOUNDRIES
}

\author{
BY
}

\author{
D. TURNER
}

From the M.R.C. Environmental Hygiene Research Unit, London, N.W.3

(RECEIVED FOR PUBLICATION SEPTEMBER 12, 1957)

In a previous paper (Turner, 1957) the results of a survey of the thermal environments in non-ferrous foundries were reported, reference was made to the index of heat stress proposed by Belding and Hatch (1955), and an indication was given of how this index could be used to evaluate the severity of the heat stress which might be encountered in foundries. A few observations were reported which showed that the required rate of heat loss by evaporation which was predicted by the index was in fair agreement with the rate observed in a sample of foundry workers.

It has been the purpose of the present study to investigate more closely the correlation between the predicted and observed rates of heat loss by evaporation under typical industrial conditions and to examine the applicability of the heat stress index for the assessment of such conditions.

\section{Methods of Measurement}

The observations were made during the summer months in two foundries in which there was a wide variety of working conditions ranging from positions round a large reverberatory furnace in a well ventilated part of the foundry where the exposure to heat was only slight, to other positions in a congested and ill-ventilated region where numerous bale-out furnaces were used and the exposure to heat was severe. Observations were made while the men worked normally for periods of between two and three hours.

Under field conditions it was not possible easily to obtain the weights of the subjects nude before and after each observation. A few such observations were made, however, and there was generally no significant change in the weight of the clothing during the period of work. This is thought to have been due to the fact that the men had been at work for some time before the observations were started, and hence their clothing had already become damp and remained in about the same condition. Thus it was felt that the changes observed in the weights of the clothed subjects could be regarded as indicating the amount of sweat lost by evaporation. Only under the most severe conditions did there appear to be much loss of sweat by dripping.

Each subject was weighed clothed before starting work and again immediately after finishing work. A careful note was taken of all fluid consumed and excreted during the working period and from this information, together with the change in weight during the period, it was possible to calculate the total quantity of fluid lost per hour. Assuming this quantity to represent the amount of sweat evaporated, the rate of heat loss by evaporation was calculated by assuming that the evaporation of 1 litre of sweat absorbs 2,400 British thermal units (B.th.U.), the figure used by Belding and Hatch.

In deriving the equations for the computation of the heat stress index Belding and Hatch calculated the heat exchanges between man and his environment with reference to a "standard man" having a surface area of 20 sq. $\mathrm{ft}$. Hence, in order that observed rates of heat loss by evaporation in the present survey should be strictly comparable with the rates calculated from the equations of Belding and Hatch, the surface area of each subject was calculated by the method of Du Bois and the observed rates of evaporation of sweat were then corrected to apply to an area of $20 \mathrm{sq}$. $\mathrm{ft}$.

The value of the heat stress index was calculated for each individual exposure. A position was chosen on the floor of the foundry where the exposure to heat was similar to the average exposure of the subject and regular measurements were made in this position, at a height of $4 \mathrm{ft} .6 \mathrm{in}$., of the wet- and dry-bulb air temperatures, the globe thermometer temperature and the air speed as measured by the kata-thermometer. The value of the heat stress index (H.S.I.) was then calculated from the equations given by Belding and Hatch:-

$$
\text { H.S.I. }=\frac{E_{\text {req }}}{E_{\max }} \times 100 \text {, or } \text { H.S.I. }=\frac{E_{\text {req }}}{2,400} \times 100
$$

The second equation was used whenever the value of $E_{\max }$ was greater than 2,400.

The quantity $E_{r e q}$ is the amount of heat which the "standard" man must lose each hour by the evaporation of sweat to maintain his body in thermal balance in the given environment. It may be calculated from a knowledge of the globe thermometer temperature $\left(t_{g},{ }^{\circ} \mathrm{F}.\right)$, the air speed $(\mathrm{V}, \mathrm{ft}$. per min.), and the metabolic rate (M, B.th.u./hr./20 sq.ft.) according to the equation:-

$$
E_{\text {rec }}=(22+2 \sqrt{ } \mathbf{V})\left(t_{g}-95\right)+M
$$

The quantity $E_{\max }$ is the amount of heat which would be absorbed if the ambient air in the given environment became saturated with water vapour at a temperature 
of $95^{\circ} \mathrm{F}$., which was assumed by Belding and Hatch to be the temperature of the skin. It may be calculated as

$$
E_{\max }=10 \cdot 3 V^{\cdot 4}\left(42-V_{P_{a}}\right)
$$

where $\mathrm{VP}_{\mathrm{a}}$ is the ambient vapour pressure, $\mathrm{mm}$. $\mathrm{Hg}$.

$E_{\max }$ is equal to 2,400 if 1 litre of sweat is evaporated each hour. Belding and Hatch proposed that this figure should be used in the calculation of the value of the index whenever $E_{\max }$ exceeded 2,400, because they held that a rate of sweating of 1 litre an hour was the most that a man should maintain over long periods.

The rate of working of an individual diecaster was variable, and there were also variations in the pattern of activity from one caster to another, due mainly to differences in the size and intricacy of the dies in use. It was impracticable to make direct measurements of the metabolic rate during the whole of each observation, and the inherent variability in the rate of working would have rendered a few accurate measurements over a short period of little value. It has been shown (Turner, 1955) that a practised observer can make subjective appraisals of the severity of manual work with reasonable accuracy and it was decided that, for the purposes of this survey, a single value so obtained for the average metabolic rate of all the casters would suffice. The typical average rate of working appeared to be about $165 \mathrm{Kcal} / \mathrm{sq} . \mathrm{m} . / \mathrm{hr}$., or about 1,200 B.th.u./hr./20 sq.ft., and this latter value has been taken as standard throughout the calculations of $E_{\text {req }}$ in these results.

\section{Results}

Ten subjects took part in this survey and altogether 98 individual observations were made. The results have been summarized in tabular form below. Table 1 shows the overall mean values and the ranges of the different variables measured, and Table 2 shows the mean values of the observed rate of heat loss by evaporation, the heat stress index, and the outside temperature for various ranges of $E_{\text {req, }}$, the rate of heat loss by evaporation required to maintain thermal equilibrium. Also in Table 2 are two indications of the difference between the observed rate of evaporative heat loss and $E_{\text {req. }}$.
TABLE 1

THE MEAN VALUES AND RANGES OF THE VARIABLES MEASURED

\begin{tabular}{|c|c|c|}
\hline & Mean & Range \\
\hline Outside air temperature $\left({ }^{\circ} \mathrm{F}.\right)$ & 68 & $52-84$ \\
\hline $\begin{array}{l}\text { Dry-bulb air temperature at working } \\
\text { position }\left({ }^{\circ} \mathrm{F} \text { ) }\right.\end{array}$ & 79 & $66-100$ \\
\hline $\begin{array}{l}\text { Wet-bulb air temperature at working } \\
\left.\text { position ( }{ }^{\circ} \mathbf{F} .\right)\end{array}$ & 64 & $52-77$ \\
\hline $\begin{array}{l}\text { Globe thermometer temperature at } \\
\text { working position }\left({ }^{\circ} \mathrm{F} \text { ) }\right.\end{array}$ & 100 & $32-120$ \\
\hline $\begin{array}{l}\text { Air speed at working position (ft. per } \\
\text { min.) }\end{array}$ & 130 & $50-260$ \\
\hline $\begin{array}{l}\text { Observed heat loss by evaporation } \\
\text { (B.th.u./hr./20 sq. ft.) }\end{array}$ & 1,560 & $700-2,750$ \\
\hline $\begin{array}{lll}\text { Ereq (B.th.u./hr./20 sq. ft.) } & \ldots & \ldots \\
\text { Heat stress index } & \text {.. }\end{array}$ & 1,440 & $\underset{26-121}{630-2,410}$ \\
\hline & & \\
\hline
\end{tabular}

For the comparison of the observed rate of evaporative loss with the value of $\mathrm{E}_{\text {req, }}$, in Table 2, the latter figure has been taken as standard. Since it is calculated from the measurements of the various thermal factors it is thought that it gives a more exact assessment of the severity of the environment than would be given by the observed rate of evaporative loss, which is based on the more variable and less accurately measured loss of weight.

For each exposure the ratio $\frac{\text { observed heat loss }}{\text { E }_{\text {req }}}$ was calculated, and the average values of this ratio for the various ranges of $E_{\text {req }}$ are given in Table 2. The deviation of the average value from unity indicates the extent of any tendency for the calculated $E_{\text {req }}$ to over-estimate or under-estimate the rate of sweating. The scatter of the individual values about the mean for each range is indicated by the root-mean-square deviation of the observed rate from $E_{\text {req }}$, expressed as a percentage of $E_{\text {req, }}$, and this is also given in Table 2.

The coefficient of correlation between $\mathrm{E}_{\text {req }}$ and the observed rate of evaporative heat loss was $0 \cdot 62$.

Discussion

Comparison of the overall mean values of $E_{r e q}$,

TABLE 2

MEAN VALUES OF VARIABLES WITH REFERENCE TO GIVEN RANGES OF RATE OF EVAPORATIVE HEAT LOSS REQUIRED TO MAINTAIN THERMAL EQUILIBRIUM (Ereq)

\begin{tabular}{|c|c|c|c|c|c|c|c|}
\hline $\begin{array}{c}\text { Range } \\
\text { of } \\
\text { Ereq }\end{array}$ & $\begin{array}{c}\text { No. of } \\
\text { Observations }\end{array}$ & $\begin{array}{c}\text { Mean Value } \\
\text { of Ereq } \\
\text { (B.th.u./hr./ } \\
20 \text { sq.ft.) } \\
\text { (a) }\end{array}$ & $\begin{array}{c}\text { Mean Value } \\
\text { of Observed } \\
\text { Evaporative } \\
\text { Heat Loss } \\
\text { (B.th.u./hr./ } \\
20 \text { sq.ft.) } \\
\text { (b) }\end{array}$ & $\begin{array}{c}\begin{array}{c}\text { Mean Value } \\
\text { of }\end{array} \\
\left(\frac{\text { Obsd. Loss }}{\text { Ereq }}\right)\end{array}$ & $\begin{array}{c}\text { Root-mean- } \\
\text { square } \\
\text { Deviation } \\
\text { of } \\
\text { (a) from }(b) \\
(\%)\end{array}$ & $\underset{\substack{\left.\text { Mean } \\
\text { External } \\
\text { Temperature } \\
{ }^{(} \mathbf{F} .\right)}}{ }$ & $\begin{array}{l}\text { Mean } \\
\text { Heat } \\
\text { Stress } \\
\text { Index }\end{array}$ \\
\hline $\begin{array}{r}600-799 \\
800-999 \\
1000-1199 \\
1200-1399 \\
1400-1599 \\
1600-1799 \\
1800-1999 \\
2000-2199 \\
2200-2399 \\
2400-2599\end{array}$ & $\begin{array}{r}10 \\
6 \\
13 \\
13 \\
23 \\
13 \\
11 \\
7 \\
0 \\
2\end{array}$ & $\begin{array}{r}650 \\
880 \\
1140 \\
1310 \\
1500 \\
1680 \\
1840 \\
2070 \\
\overline{2410}\end{array}$ & $\begin{array}{r}1080 \\
950 \\
1330 \\
1580 \\
1670 \\
1690 \\
1840 \\
1940 \\
2060\end{array}$ & $\begin{array}{l}1.67 \\
1.14 \\
1.16 \\
1.20 \\
1.12 \\
1.0 \\
1.0 \\
0.94 \\
0.85\end{array}$ & $\begin{array}{l}80 \\
18 \\
25 \\
29 \\
27 \\
27 \\
14 \\
14 \\
\frac{33}{3}\end{array}$ & $\begin{array}{l}61 \cdot 5 \\
61 \cdot 0 \\
64 \cdot 5 \\
67 \cdot 5 \\
70 \cdot 0 \\
69 \cdot 0 \\
77 \cdot 5 \\
77 \cdot 5 \\
8 \overline{82 \cdot 5}\end{array}$ & $\begin{array}{r}27 \\
37 \\
52 \\
70 \\
88 \\
80 \\
105 \\
101 \\
105\end{array}$ \\
\hline
\end{tabular}


and of the observed rates of heat loss by evaporation reveals a fair measure of agreement. The mean value of the observed rate was only $8 \frac{1}{2} \%$ in excess of the mean predicted rate and the mean value of the root-mean-square deviation was $33 \%$ (Table 1 ). If the observations in the two extreme ranges of $E_{\text {req }}$ in Table 2 are excluded from the calculations the root-mzan-square deviation is reduced to $24 \%$. This represents as good a degree of agreement as can be expected in such experiments.

The subjects were performing their normal task in the foundry. During the course of their work they moved about between the furnace and the die, yet it was only possible to measure the exposure to heat with reference to a single position, which had to be selected to represent the average exposure. Similarly an average value for the metabolic rate had to be taken, although the rate of working was variable and dependent on factors which could not be controlled. An unforeseen change in the temperature of the metal in the furnace, or a breakdown of the coating of the die, could result in a temporary change in activity.

The observed heat loss by evaporation has been calculated from the changes in weight during the working period. It was pointed out earlier that it was only possible to obtain the weights of the subjects clothed, and that this was thought to give a fair measure of the rate of evaporation of sweat.

When one bears in mind these sources of variation in the results, the agreement between the observed and required evaporative heat losses appears to be quite acceptable. There is always a considerable individual variation in the results of any study of heat losses from the human body, even when the observations are made in the laboratory with close control over the climatic conditions, the rate of working, and the precision of the weighing of the subjects. All these factors are much less controllable when surveys are made under normal industrial conditions.

The greatest deviation in the results was apparent at the lowest levels of heat stress where the observations were made in the well ventilated, uncongested part of a foundry on cool and breezy days. These conditions resulted in constantly and widely varying climatic conditions in the foundry. It may also be that the men worked harder in these cooler conditions, but it was impossible to verify this. A slight increase in the rate of working, of, say, $5 \mathrm{Kcal} /$ sq.m./hr. would have increased $E_{\text {req }}$ by between 5 and $10 \%$ in the lower ranges, and this would have reduced the disparity between the figures for $E_{r e q}$ and the observed evaporative heat losses.

It will be noted from Table 2 that the disparity between the observed values and the values of $E_{\text {req }}$ is least when $E_{r e q}$ is of the order of 2,000 . There is general agreement that the upper acceptable rate of sweating for long periods of work should be 1 litre per hour, or in terms of $E_{\text {req }}, 2,400$. As the environmental conditions approach this level it becomes more difficult to form a reliable subjective impression of the severity of the conditions, and a simple but reliable objective method of assessment is of great value. It is thus gratifying to observe such good agreement between the heat stress index and the observed rate of sweating in this particular region.

There was one occasion during this survey when it was reported that on the previous day conditions had become so hot in the foundry that the diecasters had been unable to work in the afternoon. The weather was slightly cooler on the following day, when observations were made, and the values of the heat stress index measured on that afternoon were all about 100. Again, two days later the men were complaining constantly of the heat in the foundry and on this occasion values in excess of 100 were obtained. Thus it would appear that not only does the index supply a reliable assessment of the severity of the environment in the region of the upper acceptable level, but also that conditions which result in a calculated value for the index of about $100 \mathrm{do}$, in fact, coincide closely with the upper limit of conditions for normal sustained work.

\section{Summary}

The results of 98 individual exposures to the environmental conditions occurring in typical nonferrous foundries have been reported. A comparison between the rate of heat loss by the evaporation of sweat, as calculated from the Belding-Hatch heat stress index, with the rate observed in the 10 subjects of this investigation has been made. A close agreement between the calculated and observed rates was noted, particularly in the range of environments in which the heat stress reached significant proportions. There was also some evidence to support the view that men will not willingly work for prolonged periods under conditions for which the value of the heat stress index exceeds 100 .

The author wishes to express his thanks to Dr. T. Bedford, Director, M.R.C. Environmental Hygiene Research Unit, for his encouragement during this study; and also to the managements and workers in the foundries concerned for their willing participation.

\section{REFERENCES}

Belding, H. S., and Hatch, T. F. (1955). Index for Evaluating Heat Stress in terms of Resulting Physiological Strains. Heat. Pip. Air Condit., 27, Aug., p. 129.

Turner, D. (1955). Brit. J., industr. Med., 12, 237. 